\title{
Demersal fish and epifauna associated with sandbank habitats
}

\author{
M.J. Kaiser ${ }^{a}$ *, M. Bergmann ${ }^{\text {a }}$,H. Hinz ${ }^{\mathrm{a}}$, M. Galanidi ${ }^{\mathrm{a}}$, R. Shucksmith ${ }^{\mathrm{a}}$, \\ E.I.S. Rees ${ }^{\mathrm{a}}$, T. Darbyshire ${ }^{\mathrm{b}}$, K. Ramsay ${ }^{\mathrm{c}}$ \\ ${ }^{a}$ School of Ocean Sciences, University of Wales-Bangor, Menai Bridge, Anglesey LL59 5AB, UK \\ ${ }^{\mathrm{b}}$ National Museums and Galleries of Wales, Cathays Park, Cardiff CF10 3NP, UK \\ ${ }^{\mathrm{c}}$ Countryside Council for Wales, Maes-y-Ffynnon, Penrhosgarnedd, Bangor, Gwynedd LL57 2DW, UK
}

Received 15 December 2003; accepted 16 February 2004

\begin{abstract}
A habitat specific survey of the epifauna and fish fauna of sandbanks off the Welsh coastline was undertaken in 2001. Of these, three sandbanks were considered to represent extensions of shallow nearshore soft-sediment communities, while a further six sandbanks were considered to be distinct sandbanks; seabed features clearly defined in comparison with surrounding sediments. Multivariate community analyses revealed that the distinct sandbanks had both fish and epifaunal assemblages that were distinct from those sandbanks considered to be extensions of nearshore sediments. The distinct sandbanks were typified by low species diversity and shared indicator species such as the weever fish Echiichthys vipera, the shrimp Philocheras trispinosus and the hermit crab Pagurus bernhardus. Differences occurred in species composition among the distinct sandbanks, in particular, southern sandbanks were typified by sand sole Solea lascaris and small-eyed ray Raja microocellata. The sandbanks considered as extensions of nearshore sediments shared many similarities with the Pleuronectes platessa-Limanda limanda assemblage, identified by Ellis et al. (Estuar. Coastal Shelf Sci. 51 (2000) 299), which is widespread in the Irish Sea. Sandbanks, as a habitat definition under the EU habitats directive, are likely to incorporate a number of physically and biologically distinct habitats of which two have been described in the present study.
\end{abstract}

(C) 2004 Elsevier Ltd. All rights reserved.

Keywords: sandbank habitat; fish; epifauna; quantitative survey; conservation

\section{Introduction}

The study of offshore seabed sediment habitats requires the use of remote sampling methodologies such as the use of grabs, dredges, towed video camera surveys, remote operated vehicles and trawls, all of which present their own inherent sampling artefacts and expense. These sampling constraints may explain the absence of an intensive and systematic sampling approach that might quantify the extent and variety of seabed habitats and the spatial and temporal variation in their associated assemblages. Surveys of offshore communities undertaken to date have encompassed a wide range of habitats with an emphasis

\footnotetext{
* Corresponding author.

E-mail address: michel.kaiser@bangor.ac.uk (M.J. Kaiser).
}

on description of the distribution of habitat and species assemblages made on the basis of individual sample sites separated by many kilometres and sampled with limited statistical power (e.g. Jones, 1951; Jones, 1952; Holme, 1953). Other surveys of seabed communities have occurred opportunistically as a secondary aim of large-scale surveys designed for other purposes, e.g. groundfish surveys (see Ellis et al., 2000 for a review of studies undertaken). Even where such surveys exist, for western waters off the British Isles they are undertaken at a wide scale with no sitespecific replication within the same year (Rees et al., 1999; Ellis et al., 2000). Few, if any, large-scale offshore subtidal surveys of soft-sediments have been conducted on a habitat specific basis over a wide scale.

While isolated sandbanks have been the focus of a number of studies in the past (Holme, 1949, 1953; 
Perkins, 1956; Warwick and Davies, 1977; Withers and Thorp, 1978; Tyler and Shackley, 1980) these were sitespecific studies and as such a systematic study of sandbanks within a distinct geographic region (e.g. the eastern Irish Sea) is currently lacking. Furthermore, sandbanks are difficult habitats to sample in a quantitative manner, partly due to difficulties associated with navigation (e.g. shallow water, tidal races) and the typically variable and low abundance of fauna that are encountered (Shepherd, 1983). For these reasons, sandbanks previously may have been overlooked by biologists. Sandbanks are generally formed by the physical processes of seabed currents that act in conjunction with coastal or seabed topography to lead to their formation. As a result of their unique physical regime, sandbanks may hold their own distinct assemblage of flora and fauna that is particularly well adapted to such conditions or that uses these habitats in an opportunistic manner (e.g. at slack water). The extent to which sandbanks are characterised by a distinct set of taxa however remains unknown.

Under the European Habitats Directive, sandbanks are defined as 'sublittoral sandbanks, permanently submerged' over which the 'water depth is seldom more than $20 \mathrm{~m}$ below chart datum' and are a habitat feature that requires conservation under the directive. The present study was designed to examine the fish and epifaunal biota of 9 sandbanks each of which is located within a candidate Special Area for Conservation (cSAC) (Fig. 1; Table 1).

\section{Methods}

Of the sandbanks chosen for study, Red Wharf Bay (Four Fathom Bank), Conwy Bay (Four Fathom Bank) and west of Newquay were considered to be extensions of shallow coastal sediments adjacent to the coastline, whereas the remaining sites were considered to be distinct sandbanks that are clearly defined from the surrounding seabed features and sediments (Table 1). Hyperbenthic, infaunal, epifaunal and fish samples were collected at each site from the RV Prince Madog and a full sample inventory is given in Darbyshire et al. (2002). The present study reports only the latter two components of the material collected.

At each site, five replicate tows were made with a 2-m beam trawl fitted with a chain matrix and $1-\mathrm{cm}$ square meshed net with a 1-mm codend liner (Jennings et al., 1999). The 2-m beam trawl was towed at a speed of 1.52 knots for a standard duration of 5 min timed from the moment the trawl landed on the seabed to the moment the winches began to retrieve the net. The positions of the tows were designed such that two tows were made along the shoulders of the sandbank and three tows were made on the crest of the sandbank, one of which was

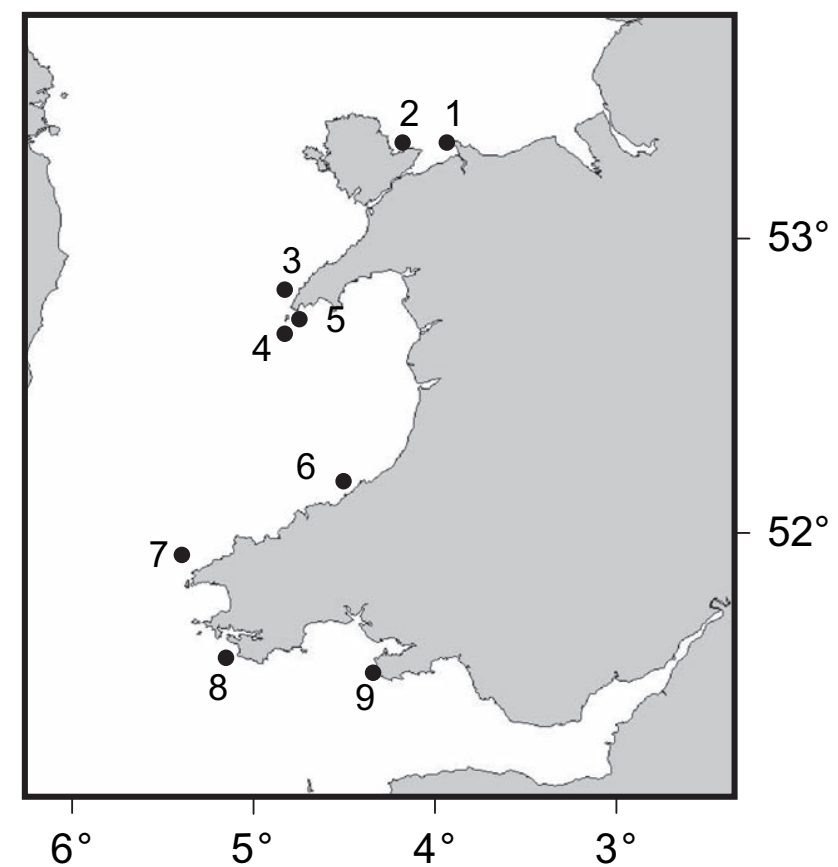

Fig. 1. Map showing the approximate positions of the sandbanks considered in the present study. $1=$ Conwy Bay, $2=$ Red Wharf Bay, $3=$ Tripods, $4=$ Bastram Shoal, $5=$ Devil's Ridge, $6=$ west of Newquay, $7=$ Bais Bank, $8=$ Turbot Bank, $9=$ Helwick Bank (east and west).

aligned along the centre of the sandbank (where such a feature existed). This sampling design was not always possible given the topography of some of the sandbanks (e.g. the Tripods). The 2-m beam trawl is a device specifically designed to sample epifaunal biota and small fish. Samples were sorted on-board ship, and were sieved over a 5-mm mesh if a large amount of inert material was present (e.g. broken shell debris). Fauna were counted and identified on-board and the total weight of each taxon determined using a motion compensated balance $( \pm 1 \mathrm{~g})$. Taxa that could not be identified were retained in $4 \%$ buffered formalin for later analysis in the laboratory.

The fish fauna was sampled using a 4-m commercial beam trawl fitted with a chain matrix and $82-\mathrm{mm}$ diamond mesh codend with a 40-mm square meshed liner (Kaiser and Spencer, 1994). At most sites, four replicate tows were made with the 4-m beam trawl which was towed at a speed of 4 knots for a standard duration of $20 \mathrm{~min}$ as above. At two sites only three or two replicate tows were made with the 4-m beam trawl due to time constraints or difficulties associated with vessel positioning relative to the sandbank and other navigational constraints. Catches were sorted on-board and processed as for the 2-m beam trawl.

At each site, sediment samples were taken using a Van Veen grab and immediately frozen on-board. In the laboratory, particle size fractions, percentage organic matter and calcium carbonate were determined 
Table 1

Summary data for each sandbank site sampled giving the environmental parameters and mean \pm s.d., total number of species, total number of individuals, Pielou's evenness and Hill's N1 and N2 indices of diversity for each sandbank site based on the abundance of fish and benthos sampled with the 2-m beam trawl and the 4-m beam trawl

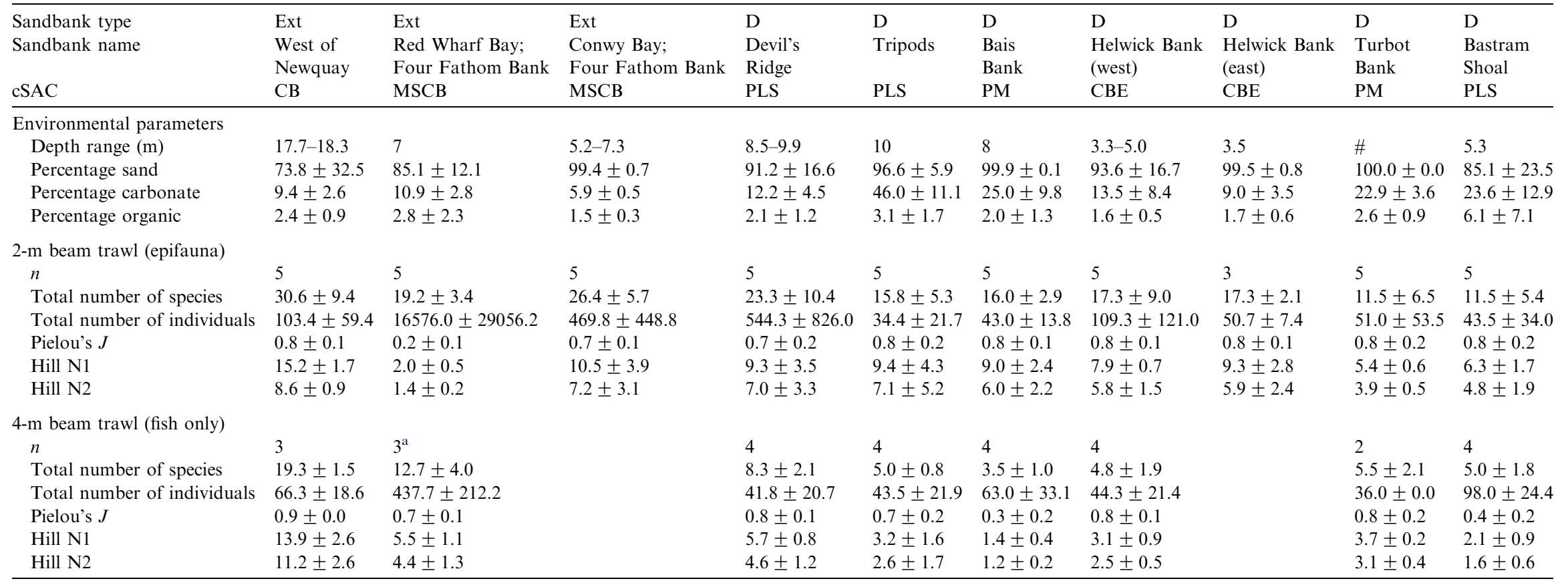

For each sandbank, the cSAC in which it is located is indicated (CB, Cardigan Bay; MSCB, Menai Strait and Conwy Bay; PLS, Pen Llyn a'r Sarnau; PM, Pembrokeshire Marine; CBE, Carmarthen Bay and Estuaries. West of Newquay, Red Wharf Bay and Conwy Bay are all extension sandbanks (Ext), while the remainder are all distinct (D) from surrounding sediments.

a One sample discarded from the analysis due to the atypically small catch for this sandbank. 
(see Holme and McIntyre, 1984 for methods) and the data categorised into the following sediment fractions: mud, muddy sand, sand, silt, carbonates and organic matter (Darbyshire et al., 2002).

At three sites (Devil's Ridge, west of Newquay and Bastram Shoal) plaice Pleuronectes platessa were collected for the purpose of dietary analyses. Dead fish had their entire stomach removed which was preserved in $4 \%$ buffered formalin. Each stomach was preserved separately in a fine-meshed bag to retain the contents such that these could be related to individual fish. Each fine-meshed bag was labelled with the total length $(\mathrm{mm})$ and weight (after removal of the stomach) (g) of the fish from which the stomach was removed. In the laboratory, stomach contents were identified to the lowest taxonomic level possible, counted and weighed after blotting on absorbent paper to an accuracy of $0.001 \mathrm{~g}$.

\subsection{Statistical analyses}

The univariate characteristics of the biological community data were calculated for the mean $( \pm$ s.d. $)$, total number of species, total number of individuals, Pielou's measure of evenness $(J)$, Hill N1 and Hill N2 indices of diversity. Hill $\mathrm{N} 1$ is the exponential of the Shannon-Wiener diversity index $(H)$ and Hill N2 is the inverse of Simpson's dominance index $(D)$ (Clarke and Warwick, 1994). Differences between sites were tested using one way ANOVA after testing that data met the criteria of normality and equal variance, and a Tukey multiple comparison test applied when significant differences were found.

The data were subjected to multivariate analyses using the PRIMER v.5 (Clarke and Warwick, 1994) software package. The entire community data set was clustered using a Bray-Curtis index of similarity on root-root transformed data. MDS ordination plots were created from the resulting similarity matrix. Differences among sites were tested a priori for statistical difference at the level of individual sites and at a broader scale to test for differences between those sites considered to be extensions of inshore soft-sediment habitats and those considered to be distinct sandbanks, using an analysis of similarities procedure (ANOSIM). In cases were replication was low (less than four), normal tests for significant differences between sites would never achieve a probability of significance lower than 0.1 . As a result the criterion for acceptance of significant differences in pair-wise comparisons of the fish fauna was set at $P=0.1$ for those comparisons were $n<4$ at one of the sites. For all other comparisons the level of significance was set at $P=0.05$. Indicator species for sites that were found to be significantly different were ascertained from an analysis of the contribution of similarity (SIMPER) made by each taxon within the samples taken at each site or broad-scale grouping of sites.
Community characteristics were related to the environmental parameters measured at each of the sandbank sites using the programme BIOENV which correlates single environmental variables individually or in multiple combinations with the similarity matrix generated from the biological data.

\section{Results}

\subsection{Epifauna (2-m beam trawl samples)}

A cluster analysis revealed that the sandbanks that are extensions of inshore shallow soft sediment (Red Wharf Bay, Conwy Bay and west of Newquay) had a greater level of similarity than sites that were considered to be distinct sandbanks (Figs. 2, 3). The outcome of this analysis was not affected by removing taxa for which there were fewer than 5 individuals in the entire data set. Significant differences occurred in community composition among sites (Figs. 2, 3, ANOSIM, $R=0.675, P<0.001)$. Pair-wise comparisons among sites revealed that the epifaunal community at Helwick Bank (east) was not significantly different from either Helwick Bank (west), Turbot Bank, Devil's Ridge or Bastram Shoal and that Devil's Ridge was not significantly different from Bastram Shoal (ANOSIM, all $P>0.054$ ). The lack of differences between Helwick Bank (east) and the other sites may be partly due to the fact that there were only three replicate tows for this site c.f. a minimum of five tows for all other sites. At a broader scale, the sandbanks that were considered as extensions of shallow subtidal sand substrata were significantly different from those considered as distinct sandbanks (Figs. 2, 3, ANOSIM $R=0.55, P<0.001$ ). The common hermit crab Pagurus bernhardus was among the most important species that contributed to similarity among samples at each site at all sites apart from Red Wharf Bay and Tripods. Similarly, the lesser weever fish Echichthys vipera was one of the most prominent species in terms of its contribution to the similarity among samples at each site except at Red Wharf Bay and Devil's Ridge (Table 2). The sandeels Ammodytes tobianus and Hyperoplus lanceolatus were found to be good indicator species at Tripods and Devil's Ridge, respectively (Table 2). In general, fewer species contributed to the overall similarity between samples collected at each site with respect to the distinct sandbanks that also had a lower mean similarity compared with the sandbanks that are extensions of adjacent subtidal sediments (from $18.1 \%$ to $50.4 \%$, c.f. $36.7 \%$ to $70.7 \%$; Table 2).

None of the measured environmental parameters indicated any major gradients that may have explained the similarity between different sandbanks based on their community composition. The best correlation was 


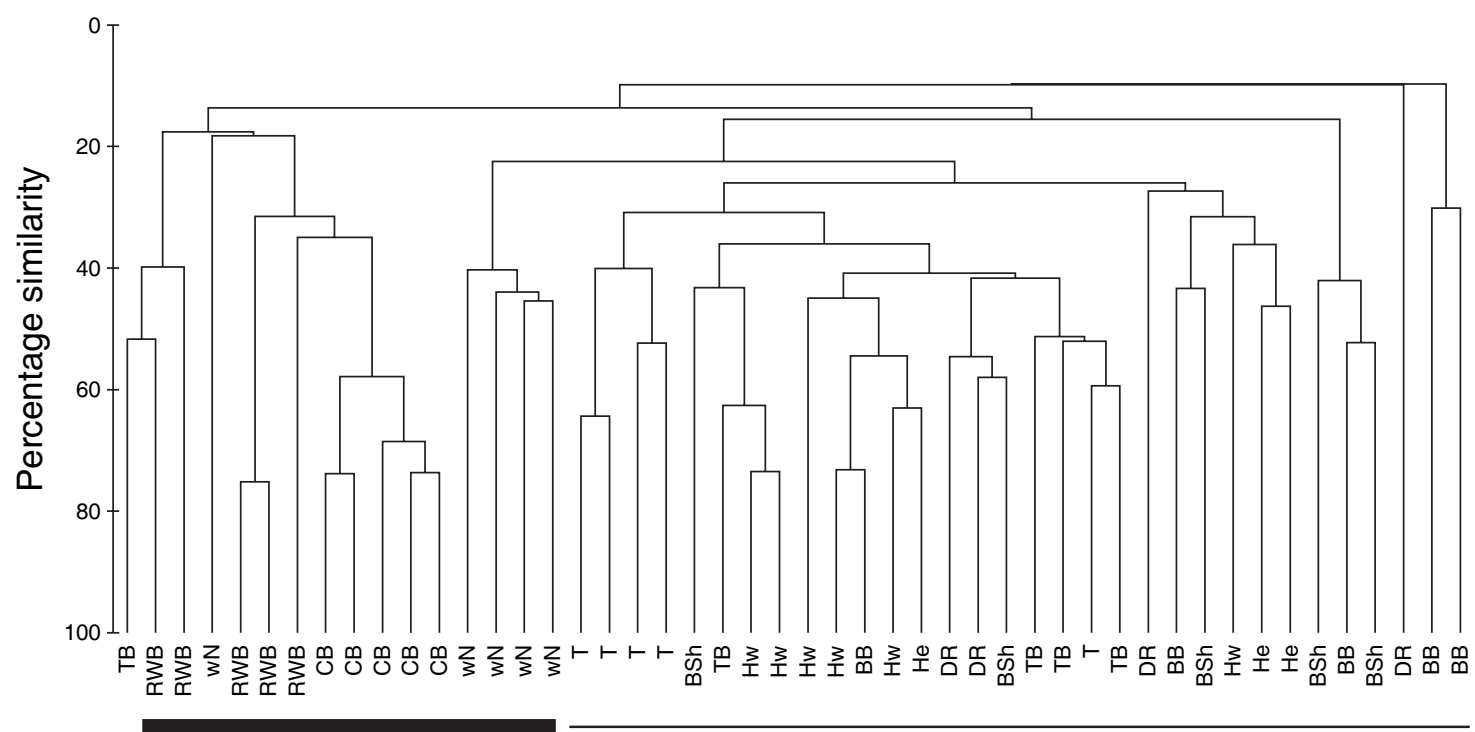

Extension sandbanks

Distinct sandbanks

Fig. 2. Cluster diagram showing the Bray-Curtis percentage of similarity among epifaunal samples collected with a 2-m beam trawl coded by site (BB, Bais Bank; BSh, Bastram Shoal; CB, Conwy Bay; DR, Devil's Ridge; Hw, Helwick Bank west; He, Helwick Bank east; RWB, Red Wharf Bay; T, Tripods; TB, Turbot Bank; wN, west of Newquay).

obtained with the percentage content of sand, but the correlation coefficient was only 0.18 . However, an examination of the univariate environmental parameters revealed that the percentage of carbonate material was significantly higher in distinct sandbanks compared with sandbanks that were extensions of adjacent subtidal soft-sediments (mean \pm s.d.; distinct sandbanks $20.9 \pm$ 13.2, extension sandbanks $8.6 \pm 2.98, t=-5.24, P<$ $0.0001)$. Neither of the other variables was found to differ significantly between the two types of sandbanks (percentage sand, $t=-1.38, P=0.10$, percentage organic content, $t=-0.86, P=0.20)$.

\subsection{Fish fauna (4-m beam trawl samples)}

A total of 35 different species of fish were encountered across the different sites of which 21 species were represented by 5 or more individuals in the data set. The

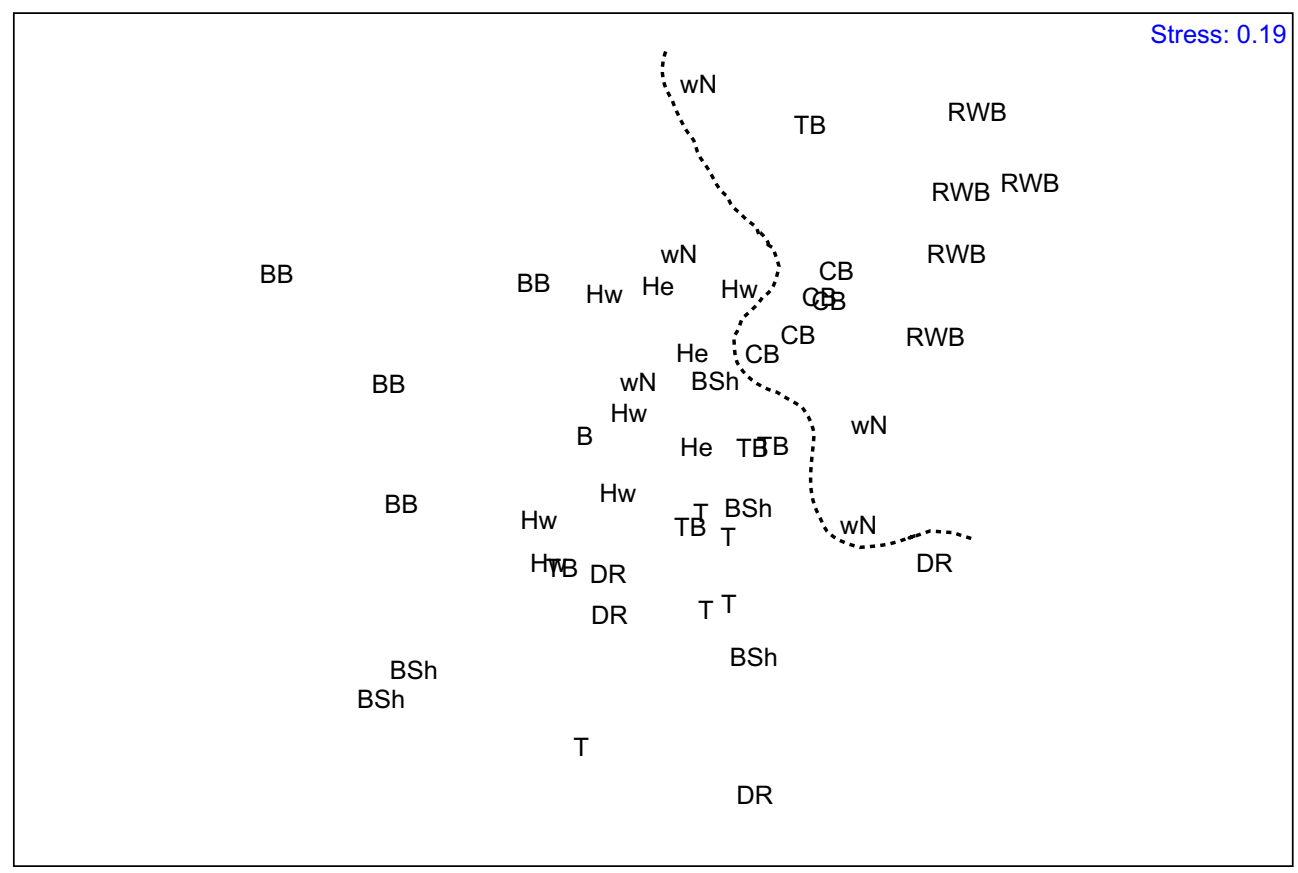

Fig. 3. MDS ordination plot giving the 2-dimensional representation of the similarity among epifaunal samples collected at each site. Site coding as for Fig. 2. 
Table 2

The outcome of a SIMPER analysis on root-root transformed data for each of the sites studied listing those species that contributed most to the similarity among samples at each site (cut-off set at $75 \%$ contribution to total similarity) with 'distinct sandbanks' shown to the right of the table

Av. Ab Av. Sim. Ratio Per. Con.

\begin{tabular}{lrllr}
\hline & Av. Ab & Av. Sim. & Ratio & Per. Con \\
\hline West of Newquay & & & & \\
Average similarity: 36.7 & & & & \\
Pagurus bernhardus & 13.4 & 4.4 & 5.2 & 11.9 \\
Callionymus lyra & 3.6 & 4.3 & 3.3 & 11.6 \\
Arnoglossus laterna & 3.0 & 2.8 & 1.1 & 7.6 \\
Echiichthys vipera & 1.6 & 2.6 & 1.1 & 7.1 \\
Pleuronectes platessa & 0.8 & 2.4 & 1.1 & 6.6 \\
Liocarcinus depurator & 1.6 & 2.4 & 1.1 & 6.6 \\
Astropecten irregularis & 1.4 & 2.1 & 1.1 & 5.8 \\
Eutrigla gurnardus & 1.4 & 2.0 & 1.1 & 5.4 \\
Ammodytes tobianus & 5.2 & 1.7 & 0.5 & 4.6 \\
Antalis entalis & 3.0 & 1.5 & 0.6 & 4.1 \\
Macropodia rostrata & 6.0 & 1.3 & 0.6 & 3.5 \\
Philocheras trispinosus & 8.8 & 1.2 & 0.6 & 3.2
\end{tabular}

\section{Conwy Bay}

Average similarity 70.7

$\begin{array}{lrrrr}\text { Pagurus bernhardus } & 38.8 & 6.5 & 6.1 & 9.2 \\ \text { Ophiura ophiura } & 222.6 & 6.4 & 8.5 & 9.0 \\ \text { Pomatoschistus minutus } & 40.6 & 6.0 & 12.6 & 8.5 \\ \text { Asterias rubens } & 30.6 & 5.4 & 14.9 & 7.6 \\ \text { Limanda limanda } & 30.6 & 4.9 & 8.5 & 7.0 \\ \text { Merlangius merlangus } & 19.4 & 4.3 & 2.0 & 6.1 \\ \text { Buglossidium luteum } & 22.2 & 4.0 & 5.1 & 5.7 \\ \text { Echiicthys vipera } & 5.4 & 3.9 & 4.8 & 5.5 \\ \text { Crangon crangon } & 8.4 & 3.7 & 6.8 & 5.2 \\ \text { Corystes cassivelaunus } & 6.2 & 3.6 & 10.0 & 5.1 \\ \text { Eutrigla gurnardus } & 3.0 & 3.6 & 6.7 & 5.0 \\ \text { Ammodytes tobianus } & 3.4 & 3.5 & 7.3 & 4.9\end{array}$

Red Wharf Bay

Average similarity 42.2

$\begin{array}{lrllr}\text { Asterias rubens } & 129.8 & 7.5 & 5.4 & 17.9 \\ \text { Liocarcinus holsatus } & 156.6 & 6.7 & 5.1 & 15.8 \\ \text { Ophiura ophiura } & 1046.6 & 5.1 & 0.6 & 12.0 \\ \text { Macropodia rostrata } & 17.8 & 3.6 & 1.2 & 8.6 \\ \text { Nucula nitidosa } & 13064.8 & 3.1 & 1.1 & 7.4 \\ \text { Astropecten irregularis } & 10.4 & 2.3 & 1.1 & 5.4 \\ \text { Polinices puchellus } & 4.6 & 2.3 & 1.1 & 5.4\end{array}$

\section{Devil's Ridge}

Average similarity 19.2

Pagurus bernhardus

Hyperoplus lanceolatus

14.4

2.0

11.2

4.9

1.

58.2

Tripods

Average similarity 50.4

$\begin{array}{lrrrr}\text { Echiichthys vipera } & 4.4 & 14.8 & 6.4 & 29.3 \\ \text { Ammodytes tobianus } & 1.4 & 11.6 & 7.3 & 23.1 \\ \text { Liocarcinus holsatus } & 2.6 & 8.0 & 1.1 & 15.9 \\ \text { Urothoe sp. (?) } & 8.0 & 4.9 & 0.6 & 9.7\end{array}$

\section{Bais Bank}

Average similarity 40.6

Pagurus bernhardus$$
24.8
$$

10.9

\section{6}

24.5

Philocheras trispinosus

3.0

9.5

Mysidacea

Echiichtys vipera

3.5

8.9

2.5

2.2

21.2

19.9

Helwick Bank (west)

Average similarity 50.4

Pagurus bernhardus
Asterias rubens
Solea lascaris
Pomatoschistus minutus
Liocarcinus holsatus
Echiichthys vipera

19.7

12.8

$\begin{array}{ll}6.3 & 10.2\end{array}$

$\begin{array}{ll}2.7 & 3.3\end{array}$

2.7

1.0

1.7

3.1

2.5

2.7

1.0

17.2

Helwick Bank (east)

Average similarity 33.8

Mysidacea
Pagurus bernhardus
Echiichthys vipera

7.2
19.4
1.6

17.9
3.8
3.3

2.2

53.1

1.6

0.6

11.2

Turbot Bank

Average similarity 37.3

Pagurus bernhardus
Echiichthys vipera
Nudibrancha indet.
Philocheras trispinosus
Liocarcinus holsatus
Ammodytes tobianus
Tunicata
Hyperoplus lanceolatus

21.8
10.8
77.2
8.8
4.6
5.4
0.6
5.0

6.3
5.5
5.2
5.1
2.5
1.8
1.6
1.5

$\begin{array}{rr}3.1 & 17.0 \\ 1.1 & 14.6 \\ 2.5 & 14.0 \\ 1.1 & 13.5 \\ 1.1 & 6.6 \\ 0.6 & 4.8 \\ 0.5 & 4.2 \\ 0.6 & 4.1\end{array}$

Bastram Shoal

Average similarity 18.1

$\begin{array}{lrlll}\text { Echiichthys vipera } & 5.8 & 8.4 & 0.5 & 46.1 \\ \text { Pagurus bernhardus } & 11.2 & 5.2 & 0.6 & 28.8 \\ \text { Philocheras trispinosus } & 2.2 & 2.7 & 0.3 & 15.1\end{array}$

$\mathrm{Av} . \mathrm{Ab}=$ average abundance, Av. Sim. = average contribution to overall similarity among samples, Ratio = the ratio of the average contribution to the overall similarity among samples to the standard deviation of the average contribution to the overall similarity, Per. Con. $=$ percentage contribution to overall similarity among samples. In cases were the ratio exceeds a value of 1.5 , these species are considered to be indicator species for that site. 
highest mean number of fish taxa was encountered on the two sandbanks that are extensions of shallow subtidal sand substrata (Table 3). The mean number of fish taxa was highest at the sandbank west of Newquay followed by Red Wharf Bay, then Devil's Ridge (Table 3 ). The remaining sites were not significantly different from each other (T-K $P>0.05)$. Cluster analysis and subsequent MDS ordination clearly demonstrated that the fish assemblages differed significantly among some of the sites (Fig. 4, ANOSIM, $R=0.67$, $P<0.001)$. As before, elimination of taxa for which there were fewer than 5 individuals in the data set did not alter the outcome of the analysis. Pair-wise comparisons among sites revealed that the fish community at Turbot Bank was not significantly different from

Table 3

Mean \pm s.d. abundance of those species that contributed most to the similarity among samples (*) collected from distinct sandbanks and those collected from sites considered to be extensions of shallow subtidal areas (shallow areas) for both the 4-m and 2-m beam trawl data

\begin{tabular}{|c|c|c|}
\hline & True sandbanks & Shallow areas \\
\hline \multicolumn{3}{|l|}{ 4-m beam trawl data } \\
\hline Echiichthys vipera & $37.0 \pm 33.6^{*}$ & $4.8 \pm 5.3^{*}$ \\
\hline Pleuronectes platessa & $3.5 \pm 3.3^{*}$ & $12.0 \pm 8.8^{*}$ \\
\hline Limanda limanda & $4.2 \pm 4.5^{*}$ & $74.5 \pm 118.3^{*}$ \\
\hline Eutrigla gurnardus & $3.8 \pm 5.4^{*}$ & $5.8 \pm 6.1^{*}$ \\
\hline Scophthalamus rhombus & $0.6 \pm 1.0 *$ & $0.0 \pm 0.0$ \\
\hline Callionymus lyra & $0.3 \pm 0.9$ & $33.0 \pm 31.3^{*}$ \\
\hline Arnoglossus laterna & $0.0 \pm 0.0$ & $16.8 \pm 17.4^{*}$ \\
\hline Buglossidium luteum & $0.0 \pm 0.0$ & $35.0 \pm 42.7^{*}$ \\
\hline Scyliorhinus canicula & $0.4 \pm 0.8$ & $3.5 \pm 3.4^{*}$ \\
\hline Agonus cataphractus & $0.1 \pm 0.5$ & $2.7 \pm 2.1 *$ \\
\hline Pomatoschistus minutus & $0.0 \pm 0.0$ & $50.5 \pm 70.4^{*}$ \\
\hline Syngnathus acus & $0.2 \pm 0.6$ & $1.0 \pm 1.1^{*}$ \\
\hline Merlangius merlangus & $0.1 \pm 0.5$ & $1.0 \pm 1.1^{*}$ \\
\hline Raja montagui & $2.1 \pm 7.1$ & $2.7 \pm 3.7^{*}$ \\
\hline \multicolumn{3}{|l|}{ 2-m beam trawl data } \\
\hline Pagurus bernhardus & $20.6 \pm 24.6^{*}$ & $24.9 \pm 19.5^{*}$ \\
\hline Asterias rubens & $5.8 \pm 8.4^{*}$ & $62.2 \pm 100.6^{*}$ \\
\hline Macropodia rostrata & $22.2 \pm 44.7$ & $11.7 \pm 14.2^{*}$ \\
\hline Ophiura ophiura & $5.0 \pm 5.7$ & $793.3 \pm 1175.0^{*}$ \\
\hline Liocarcinus holsatus & $3.9 \pm 4.1^{*}$ & $76.2 \pm 169.2^{*}$ \\
\hline Astropecten irregularis & $0.0 \pm 0.0$ & $5.8 \pm 11.0^{*}$ \\
\hline Echiichthys vipera & $6.0 \pm 7.1^{*}$ & $3.9 \pm 2.5^{*}$ \\
\hline Eutrigla gurnardus & $2.1 \pm 1.6$ & $2.4 \pm 1.0^{*}$ \\
\hline Pomatoschistus minutus & $3.0 \pm 2.2$ & $25.9 \pm 29.6^{*}$ \\
\hline Ammodytes tobianus & $3.4 \pm 5.3^{*}$ & $5.4 \pm 4.7^{*}$ \\
\hline Buglossidium luteum & $0.0 \pm 0.0$ & $16.6 \pm 20.4^{*}$ \\
\hline Crangon crangon & $2.0 \pm 0.0$ & $54.9 \pm 129.9^{*}$ \\
\hline Corystes cassivelaunus & $0.0 \pm 0.0$ & $5.5 \pm 3.5^{*}$ \\
\hline Alcyonium digitatum & $0.0 \pm 0.0$ & $6.9 \pm 15.8^{*}$ \\
\hline Pleuronectes platessa & $1.6 \pm 0.9$ & $2.4 \pm 2.5^{*}$ \\
\hline Arnoglossus laterna & $0.0 \pm 0.0$ & $3.0 \pm 2.3^{*}$ \\
\hline Limanda limanda & $1.8 \pm 0.8$ & $25.8 \pm 30.4^{*}$ \\
\hline Sepiola atlantica & $1.0 \pm 0.0$ & $2.0 \pm 1.5^{*}$ \\
\hline Philocheras trispinosus & $4.5 \pm 5.4^{*}$ & $9.2 \pm 15.7^{*}$ \\
\hline Merlangius merlangus & $0.0 \pm 0.0$ & $16.3 \pm 17.0^{*}$ \\
\hline Mysidacea & $5.8 \pm 5.5^{*}$ & $0.0 \pm 0.0$ \\
\hline Hyperoplus lanceolatus & $3.8 \pm 6.4^{*}$ & $0.0 \pm 0.0$ \\
\hline
\end{tabular}

either Bais Bank, Helwick Bank (west), or Bastram Shoal (with $P=0.1$ as only two samples were collected for Turbot Bank). Similarly, the fish community at Bais Bank was not significantly different from that at either Helwick Bank (west) or Bastram Shoal (ANOSIM, all $P>0.06$ ). As for the epifauna, the fish fauna at the two sites that were considered to be extensions of shallow nearshore sediments were significantly different from any of the other sites (Fig. 4, ANOSIM, $R=0.64$, $P<0.001)$.

A SIMPER analysis revealed those species that contributed most to the similarity between samples collected at each site. Echiichthys vipera occurred at all sites and in all but three samples. Accordingly, E. vipera was frequently the most important indicator species for most of the sites except for the Tripods and Red Wharf Bay. At a broader scale, E. vipera contributed most $(46.5 \%)$ to the similarity between sites that were considered as distinct sandbanks, followed by plaice Pleuronectes platessa, dab Limanda limanda, grey gurnard Eutrigla gurnardus and brill Scophthalamus rhombus (Table 3). For those sandbanks considered to be extensions of shallow subtidal areas, 13 species contributed most to the similarity between these sites of which the dragonet Callionymus lyra was the most important species (12.6\%) followed by scaldfish Arnoglossus laterna, plaice, dab, and thickback sole Buglossidium luteum, which contributed $57 \%$ to the overall similarity between these stations. The difference among sites best correlated with a single environmental variable: the percentage carbonate content of the sediment (correlation coefficient $=0.32)($ Fig. 5).

Although not highlighted in the SIMPER analysis, the occurrence of ray species was of interest given the conservation sensitivity of these fishes due to overfishing and their vulnerability to capture as a by-catch species. The abundance of each ray species was overlaid as a relative bubble plot on the ordination plot based on the fish fauna (Fig. 6). Three of the ray species were site specific within the context of the present study. Interestingly, Raja clavata were only encountered at the sandbanks that were extensions of adjacent shallow softsediments and were not found on the distinct sandbanks. Raja brachyura and Raja microocellata were only encountered on distinct sandbanks, the latter on southern sandbanks and the former on more northerly sandbanks. Raja microocellata captured in the present study were mainly mature adult fish. Raja montagui were more broadly distributed across all sandbank types.

\subsection{Plaice diets}

The plaice sampled were on average smallest at west of Newquay $(64.0 \pm 61.2$, comparison with both Devil's Ridge and Bastram Shoal; $t=4.75, P<0.0001$ ), whereas they were of similar size at Devil's Ridge and 


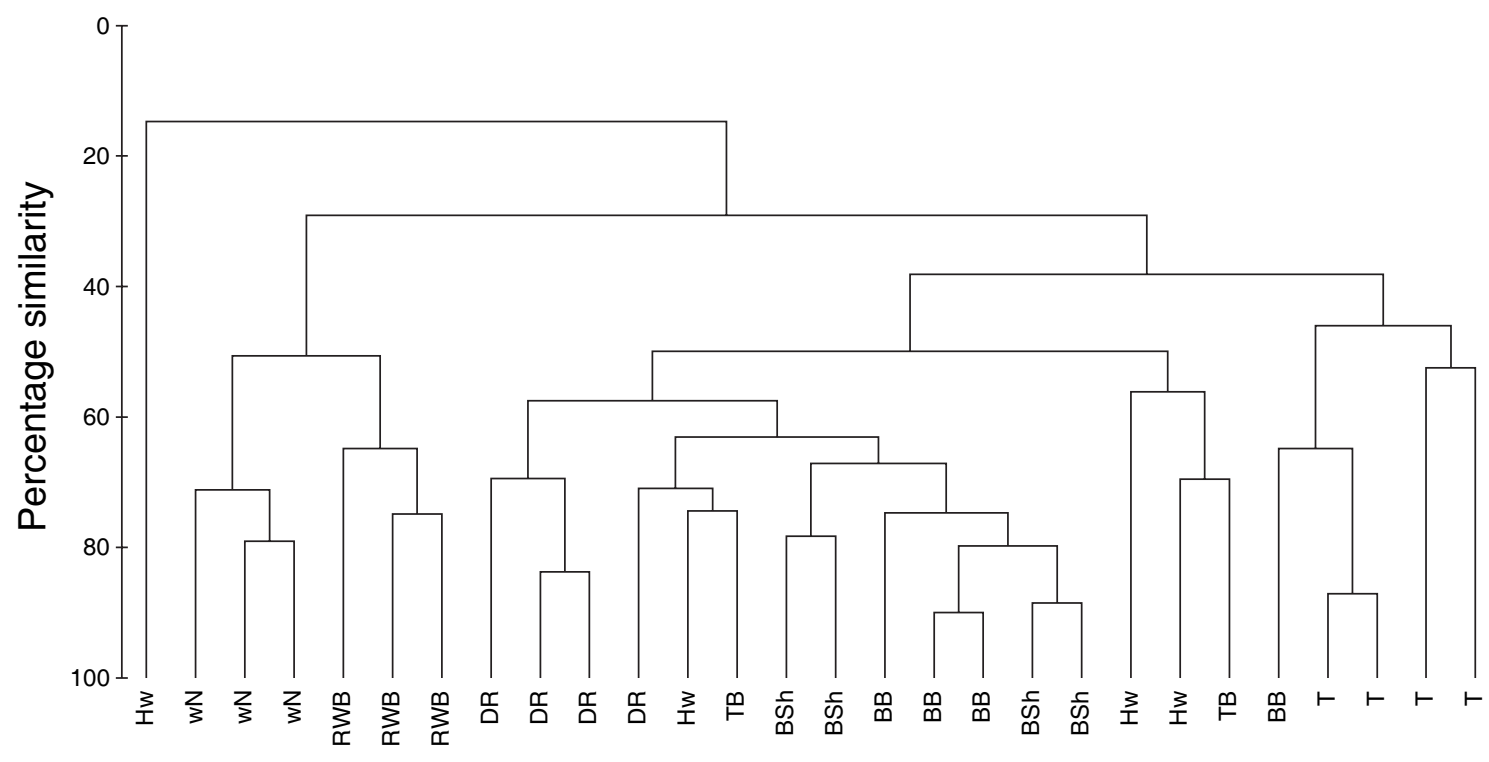

Extension sandbanks

Distinct sandbanks

Fig. 4. Cluster diagram showing the Bray-Curtis percentage of similarity among fish samples collected with a 4-m beam trawl coded by site as for Fig. 2.

Bastram Shoal (mean \pm s.d., Devil's Ridge $151.0 \pm$ $62.0 \mathrm{~g}$, Bastram Shoal $183.0 \pm 106.7 \mathrm{~g} ; t=-1.30$, $P=0.10)$. At each site, relatively few stomachs contained prey (Devil's Ridge (10), west of Newquay (14), Bastram Shoal (14)). Accordingly, the number of dif- ferent species of prey that occurred in the diet of fish sampled from Devil's Ridge was lower (8 species) than at the other sites (west of Newquay (14 species), Bastram Shoal (11 species)), but this was probably related to lower sampling effort. Of the prey eaten, sandeels

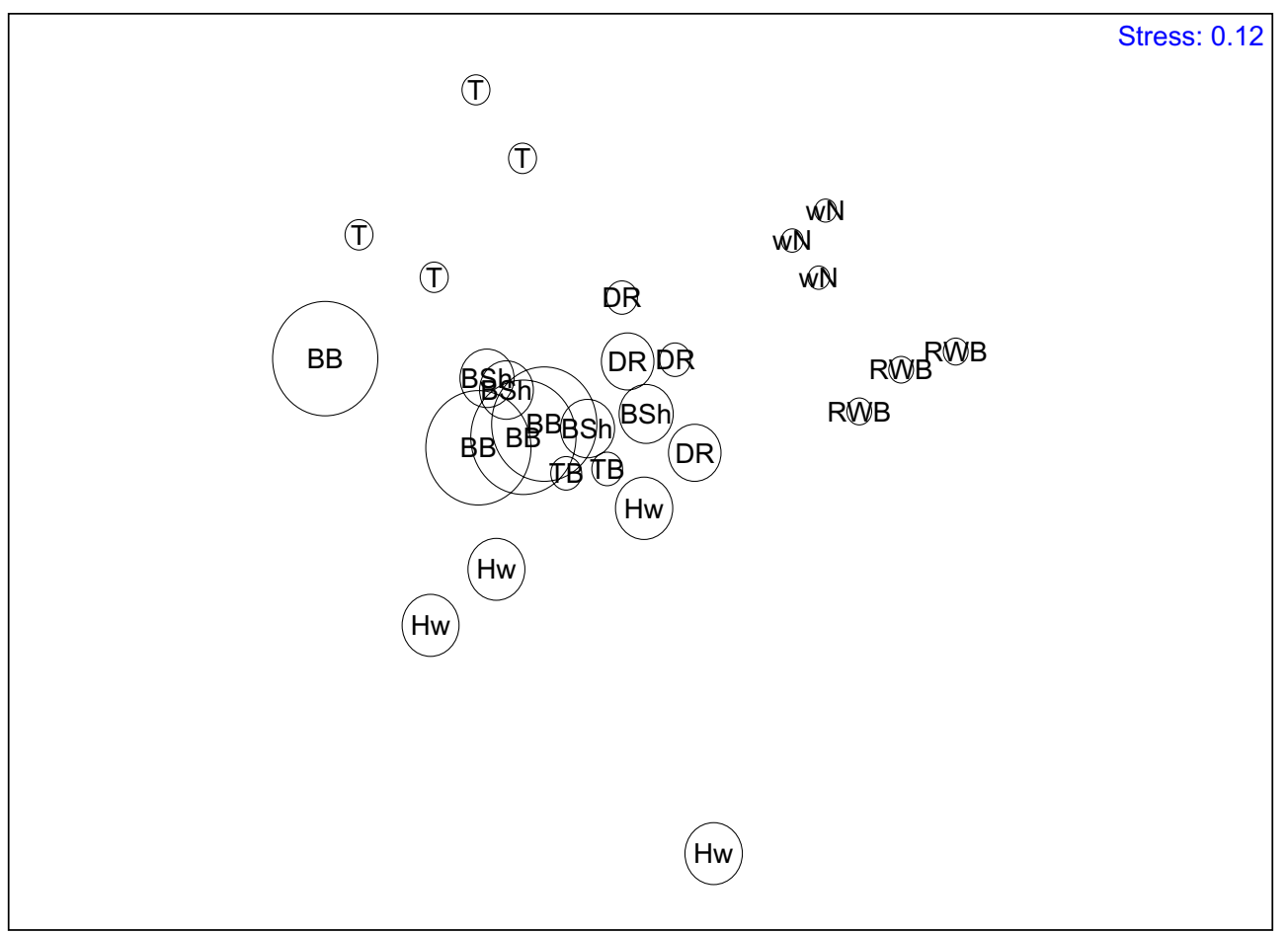

Fig. 5. MDS ordination plot giving the 2-dimensional representation of the similarity among fish fauna samples collected at each site with the relative percentage carbonate content of the sediment of those sites overlaid as bubble plots. The larger the bubble the greater the percentage carbonate content of the sediment. Extension sandbanks (RWB and wN) have the lowest carbonate content. 


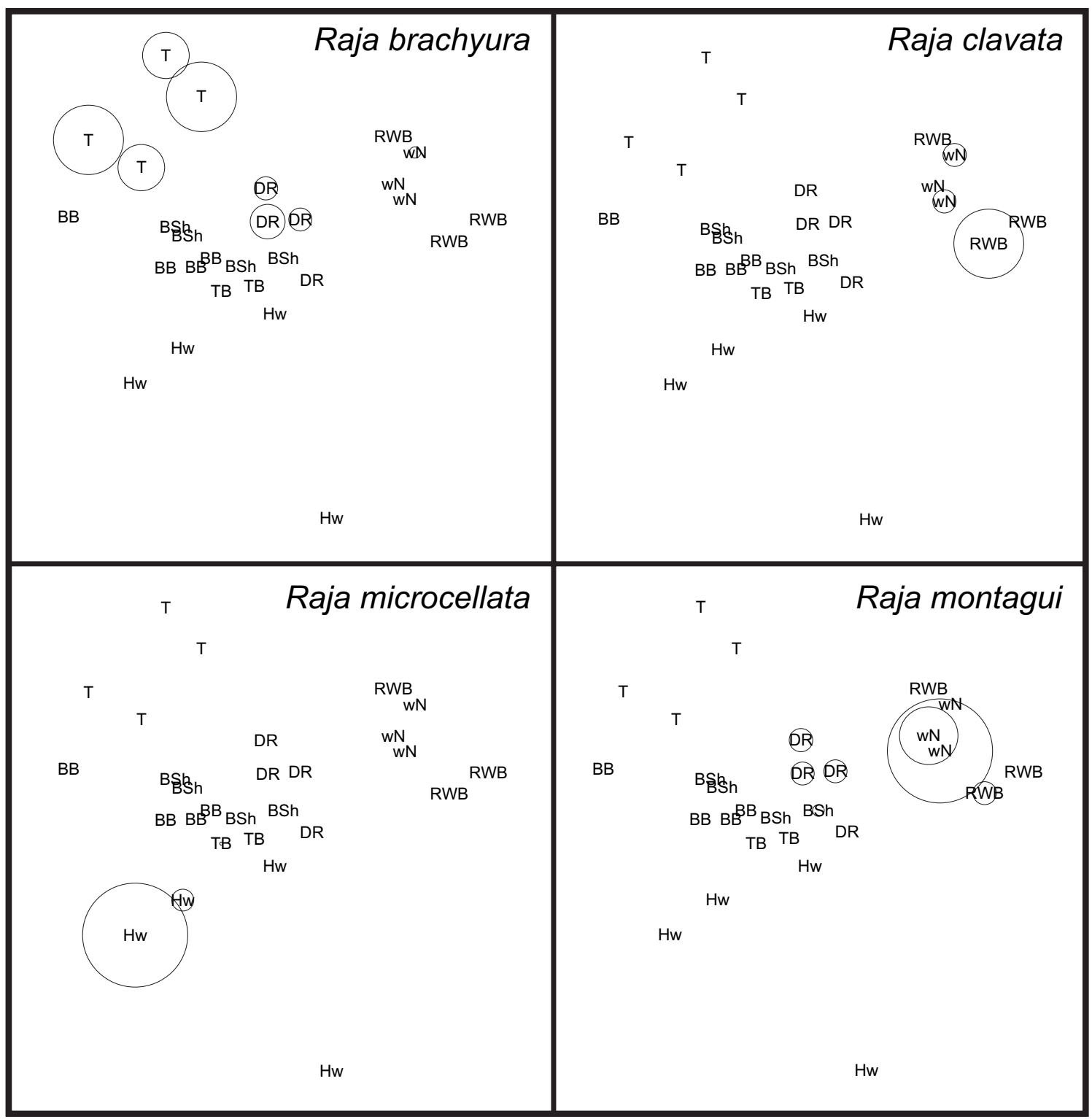

Fig. 6. MDS ordination plot giving the 2-dimensional representation of the similarity among fish fauna samples collected at each site with the relative abundance of four ray species that occurred at certain sites overlaid as bubble plots. The larger the bubble the greater the number of rays of a particular species captured at that site.

Ammodytes tobianus contributed most to total weight of prey in the diet at the two distinct sandbanks, whereas the importance of prey (by weight) west of Newquay was spread among sandeels, polychaetes and solenidae. As the fish sampled west of Newquay were on average smaller, it is perhaps not surprising that they incorporated a relatively larger range of small body-sized prey in their diet (Fig. 7).

\section{Discussion}

More generally, the few specific surveys of the benthos of sand bank habitats have tended to focus on the infaunal components that are sampled with benthic grabs (e.g. Warwick and Davies, 1977; Vanosmael et al., 1982; Rees and Eleftheriou, 1989; Degraer et al., 1999; Rees et al., 1999) which reduces comparability with the present study. Although there are previous studies of the macrozoobenthos and fish fauna of the North Sea and English Channel, these were not habitat specific to sandbanks and encompassed a wide range of habitats (e.g. Jennings et al., 1999; Kaiser et al., 1999). Indeed, the samples collected in these studies may represent the fauna sampled from several different habitats during the period the sampling gear was towed over the seabed, some of which may incorporate sandbank fauna mixed with fauna from adjacent habitats. Thus, as so few authors have sampled sandbanks specifically using quantitative sampling devices, wider comparison is difficult 

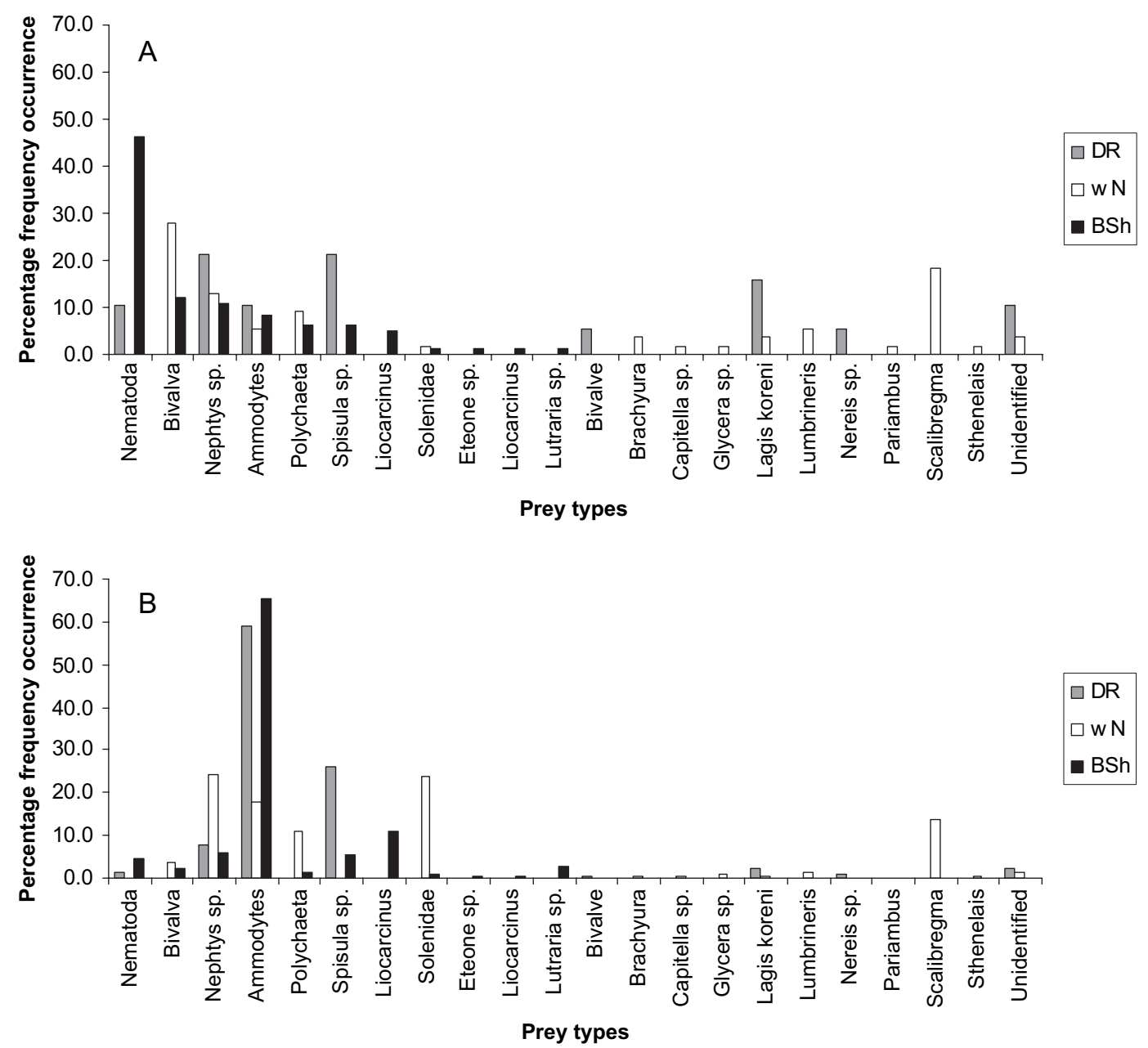

Fig. 7. The percentage frequency occurrence of different prey types identified from the stomach contents of plaice sampled at three sites (Devil's Ridge (DR), Bastram Shoal (BSh) and west of Newquay (wN)) based on abundance (A) and biomass (B).

although it is likely that the present general community observations are applicable to sandbanks elsewhere.

Previous studies undertaken in the Irish Sea have been conducted with different objectives and have used a variety of different sampling devices from grabs, to box corers to trawls (e.g. Jones, 1951; Swift 1993; Ellis et al., 2000). Even when such surveys overlap, it is difficult to compare directly the results obtained because each sampling device samples at a different scale $\left(0.1 \mathrm{~m}^{2}\right.$ for grabs; $0.2 \mathrm{~m}^{2}$ for box corers; $100 \mathrm{~s}-1000 \mathrm{~s} \mathrm{~m}^{2}$ for trawls). Furthermore, individual devices sample effectively on only a proportion of the benthic assemblage, hence the grain of information gained varies between studies such that they are not comparable if a wide-scale interpretation of the data is to be undertaken. When a full understanding of community structure is required it is necessary to adopt a variety of sampling methodologies to sample adequately at all scales. In the present study, two scales of sampling $600 \mathrm{~m}^{2}$ (2-m beam trawl) and $9600 \mathrm{~m}^{2}$ (4-m beam trawl) were used to quantify the epibenthic and fish fauna of sandbank habitats. While the 4-m beam trawl will sample epifauna effectively (Kaiser et al., 1999; Ellis et al., 2000) it will tend to sample only larger macrofauna efficiently and will miss many of the smaller body-sized $(<10 \mathrm{~mm})$ fauna or under-represent their importance in the assemblage. For wide-scale surveys in which the objective is to provide a comprehensive description of the broad distribution of community types, low (no) replication is the norm given the trade-off of sampling effort required to sample a large number of stations. In the present study however, the main aim was to undertake a detailed description of communities at a relatively small number of sites spread across a regional area, thus sample replication was of paramount importance especially given the experience of previous authors who have attempted to describe the communities associated with sandbanks in the past (e.g. Shepherd, 1983).

In the present study, it is clear that the sandbanks that are extensions of shallow nearshore soft-sediments are well defined from the distinct sandbank habitats both in terms of their fish and epifaunal communities. In general, 
species diversity and abundance of individuals were lower for distinct sandbanks, which is not surprising given the dynamic environment in which most of these sandbanks were located. The percentage of carbonate content of the sediment sampled at the distinct sandbanks was higher than that for the other sites which would concur with areas of the seabed subjected to strong tidal scour that will have larger sediment particles in sandy habitats. In the present study, much of the sandy sediment sampled had a large proportion of shell-hash of varying particle sizes which would explain the higher percentage carbonate content (MJK personal observations). At one site (Devil's Ridge) the 2-m beam trawl catch contained an extraordinary number of empty and scoured common whelk Buccinum undatum shells that were not occupied by hermit crabs despite the prevalence of the latter. Many of these shells were highly degraded in condition, but were not encrusted with epibiota. The distinct sandbanks were typified by a very restricted number of species that included Pagurus bernhardus, Asterias rubens, Liocarcinus holsatus, Echichthys vipera, Ammodytes tobianus, Philocheras trispinosus, Hyperoplus lanceolatus, and Mysidacea for the epifaunal community (sampled with the 2-m beam trawl) and Pleuronectes platessa, Limanda limanda, Eutrigla gurnardus, Scophthalamus rhombus for the fish community. Ellis et al. (2000) undertook a similar analysis of data from a wide-scale survey of groundfish and benthos sampled with a 4-m beam trawl as used in the present study. They described a distinct faunistic association for inshore sandy areas that extended from south to north Wales (Pleuronectes platessa-Limanda limanda association) (Ellis et al., 2000). A comparison of the assemblages identified for the distinct sandbanks targeted in the present study matches only 5 species with a compliment of 21 identified by Ellis et al. (2000) for the inshore sandy habitats. However, a comparison of the sandbanks considered to be extensions of inshore sandy areas in the present study with the same association yielded 13 species in common. It should be noted that the association identified by Ellis et al. (2000) was based on a sample of 43 stations. This indicates that there is close agreement between the assemblage identified for the sandbanks considered to be extensions of inshore shallow sediments and that defined by Ellis et al. (2000). The distinct sandbanks defined in the present study are typified by a much more restricted set of species which ranged from only two at Devil's Ridge to eight at Turbot Bank. Furthermore, common weevers were often the most important species at these sites and these did not feature in any of Ellis et al.'s (2000) assemblages. Other key indicator species for the distinct sandbanks included common hermit crabs, greater and lesser sandeels, Solea lascaris - a southern species of sole-the goby Pomatoschistus minutus, Mysidacea, and P. trispinosus.

Although not listed as those species that contributed most to the similarity between stations, rays are of conservation interest given their vulnerability to overfishing (Dulvy and Reynolds, 2002). Four different ray species were encountered during the survey of which three showed differences in habitat preference. The thornback ray Raja clavata occurred only on the sandbanks considered to be extensions of inshore soft-sediment habitats and did not occur on the more dynamic distinct sandbanks which is noteworthy. In contrast the blonde ray Raja brachyura only occurred at more northerly sandbanks while the small-eyed ray Raja microocellata occurred only at southerly sandbanks, and in particularly high numbers at Helwick Bank (Fig. 5). The latter also tended to co-occur with another southern species the sand sole Solea lascaris. The present study does not imply that $R$. microocellata is found exclusively on sandbank habitats as it is known that they are also found in sandy bays in the southern Irish Sea and Bristol Channel (J.R. Ellis, pers. comm.).

Although plaice were sampled in order to examine their diet in relation to food available on the sandbanks, they were caught in sufficient numbers at too few sites for meaningful analysis. However, is was clear that fish from the distinct sandbanks Devil's Ridge and Bastram Shoal were on average larger than those caught west of Newquay. At both of the former sites, sandeels Ammodytes tobianus were the most important prey in terms of their contribution to the overall diet. The smaller fish sampled west of Newquay had a broader diet that included mostly small prey-types such as polychaetes, which concurs with earlier studies (Fig. 6) (Jones, 1952).

The distinct sandbanks studied herein would appear to be different from the assemblages identified by Ellis et al. (2000). However, the sites considered to be extensions of nearshore shallow soft-sediments appear to be very similar to the Pleuronectes platessa-Limanda limanda assemblage described by Ellis et al. (2000), which appears to be widespread throughout the Irish Sea below the $20 \mathrm{~m}$ depth contour. Thus while the sandbanks considered to be extensions of shallow nearshore sediments in the present study are considered to be representative of this widespread benthic and fish assemblage, Devil's Ridge, Tripods, Bais Bank, Helwick Bank (east and west), Turbot Bank and Bastram Shoal would all appear to have distinct assemblages of their own with some common constituents (e.g. weever fish and hermit crabs) and other geographically restricted components (e.g. Solea lascaris).

\section{Acknowledgements}

The authors wish to thank the Master and crew of the RV Prince Madog, colleagues of the National Museum of Wales Cardiff and the Countryside Council for Wales and David Cocks for field work assistance. Jim Ellis is thanked for his constructive comments on an earlier version of the manuscript. 


\section{References}

Clarke, K.R., Warwick, R.M., 1994. Change in Marine Communities: an Approach to Statistical Analysis and Interpretation. Natural Environmental Research Council, Plymouth Marine Laboratory, Plymouth, UK, 144 pp.

Darbyshire, T., Mackie, A.S.Y., May, S.J., Rostron, D., 2002. Macrofaunal survey of Welsh sandbanks 2001. Countryside Council of Wales Contract Report No. 539, Countryside Council for Wales, Bangor, UK, $113 \mathrm{pp}$.

Degraer, S., Vincx, M., Meire, P., Offringa, H., 1999. The macrozoobenthos of an important wintering area of the common scoter (Melanitta nigra). Journal of the Marine Biological Association of the United Kingdom 79, 243-251.

Dulvy, N.K., Reynolds, J.D., 2002. Predicting extinction vulnerability in skates. Conservation Biology 16, 440-450.

Ellis, J.R., Rogers, S.I., Freeman, S.M., 2000. Demersal assemblages in the Irish Sea, St George's Channel and Bristol Channel. Estuarine, Coastal and Shelf Science 51, 299-315.

Holme, N.A., 1949. The fauna of sand and mud banks near the mouth of the Exe Estuary. Journal of the Marine Biological Association of the United Kingdom 28, 189-237.

Holme, N.A., 1953. The biomass of the bottom fauna in the English Channel off Plymouth. Journal of the Marine Biological Association of the United Kingdom 32, 1-32.

Holme, N.A., McIntyre, A.D., 1984. Methods for the Study of Marine Benthos. Blackwell Scientific Publications, Oxford, UK, 387 pp.

Jennings, S., Lancaster, J.E., Woolmer, A., Cotter, J., 1999. Distribution, diversity and abundance of epibenthic fauna in the North Sea. Journal of the Marine Biological Association of the United Kingdom 79, 385-399.

Jones, N.S., 1951. The bottom fauna off the south of the Isle of Man. Journal of Animal Ecology 20, 132-144.

Jones, N.S., 1952. The bottom fauna and the food of flatfish off the Cumberland coast. Journal of Animal Ecology 21, 182-205.

Kaiser, M.J., Spencer, B.E., 1994. Fish scavenging behaviour in recently trawled areas. Marine Ecology Progress Series 112, 41-49.
Kaiser, M.J., Rogers, S.I., Ellis, J.R., 1999. Importance of benthic habitat complexity for demersal fish assemblages. American Fisheries Society Symposium 22, 212-223.

Perkins, E.J., 1956. The fauna of a sandbank in the mouth of the Dee estuary. Annals of the Magazine of the Natural History Series 12, $112-128$

Rees, H., Eleftheriou, A., 1989. North Sea benthos: a review of field investigations into the biological effects of man's activities. Journal du Conseil, Conseil International pour l'Exploration de la Mer 45, 284-305.

Rees, H.L., Pendle, M.A., Waldock, R., Limpenny, D.S., Boyd, S.E., 1999. A comparison of benthic biodiversity in the North Sea, English Channel and Celtic Seas. ICES Journal of Marine Science 56, 228-246.

Shepherd, S.A., 1983. The epifauna of megaripples: species' adaptations and population responses to disturbance. Australian Journal of Ecology 8, 3-8.

Swift, D.J., 1993. The macrobenthic infauna off Sellafield (Northeastern Irish Sea) with special reference to bioturbation. Journal of the Marine Biological Association of the United Kingdom 73, 143-162.

Tyler, P.A., Shackley, S.E., 1980. The benthic ecology of linear sandbanks: a modified Spisula sub-community. In: Collins, M.B., Banner, F.T., Tyler, P.A., Wakefield, S.J., James, A.E. (Eds.), Industrial Embayments and Their Environmental Problems. A Case Study of Swansea Bay. Pergamon Press, Oxford, UK, pp. 539-551.

Vanosmael, C., Willems, K.A., Claeys, D., Vincx, M., Heip, C., 1982. Macrobenthos of a sublittoral sandbank in the Southern Bight of the North Sea. Journal of the Marine Biological Association of the United Kingdom 62, 521-534.

Warwick, R.M., Davies, J.R., 1977. The distribution of sublittoral macrofauna communities in the Bristol Channel in relation to the substrate. Estuarine, Coastal and Shelf Science 5, 267-288.

Withers, R.G., Thorp, C.H., 1978. The macrobenthos inhabiting sandbanks in Langstone Harbour, Hampshire. Journal of Natural History 12, 445-455. 